\title{
Atuação das Associações Escolares Notre Dame no contexto da colonização em Maravilha/SC (1954-1976)
}

\author{
Act of the Notre Dame School Associations in the context \\ of colonization in Maravilha/SC (1954-1976)
}

Vitor Marcelo Vieira*

Palavras-chave:

Associações Escolares

Congregação de Notre Dame

Processo de Colonização

Keywords:

School associations

Congregation of Notre Dame

process of colonization
Resumo: O objetivo deste artigo é analisar as atividades que as Associações Escolares desempenhavam no interior e no entorno do Grupo Escolar Nossa Senhora da Salete, conduzido pela Congregação das Irmãs de Notre Dame, no contexto da colonização em Maravilha/SC, entre 1954 e 1976. O período, marca a chegada das irmãs à Vila Maravilha, como era chamado o local, e o encerramento das atividades das religiosas à frente da escola no final da década de 1970. A investigação em documentos contempla o período em que a ordem religiosa protagonizou os rumos educacionais no povoado. Estudar esse recorte é ter em mente que o historiador: "é sempre de um tempo, aquele em que o acaso o fez nascer e do qual ele abraça, às vezes sem o saber, as curiosidades, as inclinações, os pressupostos [...] postulados de sua época" (RÉMOND, 2003, p. 14). Assim, a escolha dos documentos é no sentido de apresentar elementos e inquietações que estão presentes, e que faz parte da tese de Doutorado em História desse autor. A escolha do recorte temporal busca investigar a atuação das Associações Escolares Notre Dame no contexto da colonização, com a presença de colonos que migraram do Rio Grande Sul.

Abstract: The objective of this article is to analyze the activities that the School Associations carried out in and around the Nossa Senhora da Salete School Group, conducted by the Congregation of the Sisters of Notre Dame, in the context of colonization in Maravilha/SC, between 1954 and 1976. The period marks the arrival of the sisters at Vila Maravilha, as the place was called, and the closing of the activities of women religious at the head of the school in the late 1970s. The documentary investigation contemplates the period in which the religious order carried out education in the village. Studying this clipping is to keep in mind that the historian: "it is always of a time, the one in which chance caused him to be born and from which he embraces, sometimes unknowingly, curiosities, inclinations, presuppositions [...] postulates of his time" (RÉMOND, 2003, p.14). Thus, the choice of documents is to present elements and concerns that are present, and that is part of the PhD thesis in History of this author. The choice of the temporal cutout investigates the performance of Notre Dame School Associations in the context of colonization, with the presence of settlers who migrated from Rio Grande Sul.

Recebido em 29 de maio de 2018. Aprovado em 30 de julho de 2018.

O caderno mais íntimo, largado em um canto de sótão e encontrado alguns séculos depois, sugere que, apesar de tudo, quem o escreveu pretendia de algum modo ser descoberto $e$ acreditava que os acontecimentos de sua vida tinham de ser redigidos ${ }^{1}$

\footnotetext{
* Graduado em História - licenciatura plena pela Universidade Comunitária da Região de Chapecó (Unochapecó); Especialista em Educação pela Universidade do Oeste de Santa Catarina (Unoesc); Graduado em Sociologia - licenciatura plena pela Universidade Comunitária da Região de Chapecó (Unochapecó/Parfor); Mestre em História pela Universidade de Passo Fundo (UPF); Doutorando do Programa de Pós-Graduação em História da Universidade do Estado de Santa Catarina (UDESC). Professor efetivo de História e Sociologia na EEB. Lourdes Lago e EEB. Alexandre Cella em Chapecó/SC. E-mail: vitormarcelov@yahoo.com.br.
} 


\section{Introdução}

A proposta deste artigo é trazer reflexões que problematizem a presença de associações escolares dentro dos muros do Grupo Escolar Nossa Senhora da Salete em Maravilha/SC entre os anos de 1954 e 1976. O tema abordado neste texto relacionase ao contexto do processo de colonização, com a presença de famílias oriundas do Rio Grande do Sul, que aportaram a essa região do Oeste Catarinense, ${ }^{2}$ mais especificamente em Maravilha/SC, a partir do final dos anos 1940.

As famílias e principalmente os filhos desses colonos oriundos do Rio Grande do Sul são os sujeitos diretamente envolvidos nessa atmosfera religiosa educacional, a qual tem como protagonista a Congregação das Irmãs de Notre Dame, uma ordem religiosa presente no palco da colonização e que tinha sua sede em Passo Fundo/RS. Em 1954, chegou a então Vila Maravilha para tratar da missão de cuidar dos assuntos educacionais junto aos filhos dos colonos.

As categorias escolhidas foram o controle e a disciplina que surgiram a partir da análise dos documentos. Navegar por tal seara leva indubitavelmente à necessidade de o historiador manter distância variável em relação ao objeto estudado. No entanto:

Há proximidade porque se estuda um processo em curso, inacabado por definição, ou porque se trata de um ator vivo, acessível e, portanto, sujeito a reações diante das afirmações do historiador. Há distância relativa porque o processo é, apesar de tudo, datado ou o tema mais velho que o observador: encontra-se essa ideia central de que o tempo presente define uma duração significativa e não um instante fugaz. (ROUSSO, 2016, p. 240).

Para tanto, o que se busca, a partir da complexidade dessa teia de relações, que se estabeleceram nesse espaço e tempo, dentro e além-muro da escola, são elementos que mostrem como essas associações atuavam e reproduziam os discursos de Notre Dame, difundidos socialmente naquele momento, que estavam inseridas no cenário maior do processo de colonização. Para isso, foi preciso aproximar mais a lente, para observar os detalhes dessas relações.

A documentação analisada, ou seja, o acervo de Notre Dame faz parte do arquivo passivo da Escola de Educação Básica Nossa Senhora da Salete de Maravilha/SC e da Casa Provincial, sediada em Passo Fundo/RS. Os anais que estão na Casa Provincial tem sua origem, na Casa Nossa Senhora da Salete, residência onde moravam as irmãs em Maravilha.

As atividades das religiosas e da comunidade eram registradas em relatórios anuais. A Casa Provincial de Notre Dame tinha as diretrizes com relação aos anais. A superiora local deveria cuidar para que os anais fossem escritos e enviados à Casa Provincial e ao Generalato em Roma, na Itália. Com relação à finalidade, conforme as diretrizes de dezembro de 1982: "Os anais têm por fim dar um resumo estatístico das atividades da casa e narrar em ordem cronológica os principais acontecimentos do ano". Portanto, uma das irmãs era responsável pela escrita. Escrevia, para que as assistentes gerais e a secretária geral pudessem ler, na Casa Provincial.

As irmãs de Notre Dame chegaram ao povoado Vila Maravilha, ${ }^{3}$ em 1954. Nesse mesmo ano, chegaram ao local, os Missionários da Sagrada Família. ${ }^{4} \mathrm{~A}$ chegada de ambas as ordens religiosas não foi por acaso. Existia interesse da colonizadora na valorização das terras; para isso, a presença das religiosas era um atrativo a mais para a venda das terras, além de se estabelecerem no centro do território colonizado. As irmãs viriam para educar os filhos dos colonos de origem. ${ }^{5}$ A colonizadora, para atrair os compradores e convencê-los a adquirirem as terras, oferecia a possibilidade da prática religiosa para os migrantes e, principalmente, educação para seus filhos. Encontramos um exemplo disso quando percebemos que a religiosidade dos colonos era significativa e que a Colonizadora sabia da importância da religião para atrair novas famílias de colonos (WERLANG, 2006).

No ano da instalação do município de Maravilha, a Congregação das Irmãs de Notre Dame já atuava no povoado, juntamente com os padres Missionários da Sagrada Família de Passo Fundo/ 
RS. Nos anais do ano de 1958, a irmã Maria Ancila, diretora do Grupo Escolar, disse o seguinte sobre a instalação do município de Maravilha, ocorrido no dia 27 de julho de 1958: "De máxima importância é o dia de hoje para a nossa povoação, que com apenas 8 anos de existência passou a ser município" (ANAIS CASA N. S. DA SALETE, 1958, p. 18). Seis anos antes, em 1952, foi enviada uma carta para a matriz da colonizadora Companhia Territorial Sul Brasil, em Porto Alegre/RS, assinada pelo diretorgerente, José Leal Filho, e pelo padre Antônio Hammelnstein, solicitando uma quadra para a construção de uma casa para o funcionamento da escola. A carta diz o seguinte:

Encontra-se aqui presente, o Revmo. Padre Antônio Hammelstein, que deseja recordar uma palestra mantida com V.S., na presença do signatário, sobre a concessão da quadra urbana $n^{\circ}$ 4, da Séde Maravilha, para a Mitra da Prelazia de Palmas, afim de que S, Exa., o Sr. Bispo Titular da mesma, providencie na indicação de uma Ordem de Irmãs Religiosas que ai venham estabelecer um colégio. - O Revdmo. Padre Antônio, deseja ocupar a referida quadra e nela construir uma casa para funcionar a Escóla, atualmente sediada no estabelecimento inicial do futuro Seminário dos Missionarios da Sagrada Família, casa esta que será futuramente entregue às Irmãs educacionistas. - Transmitindo as intensões do Revmo. Padre Antônio Hammelstein, esperamos as determinações de V.S., a respeito (CARTA À CIA. SUL BRASIL, Cunha Porâ/SC, 26 maio 1952). ${ }^{6}$

O pedido, que se refere à construção de uma casa para as irmãs para servir de escola, veio a se concretizar somente em 1957. É a partir desse ponto que vamos abordar o papel desempenhado pelas associações escolares inseridas no contexto da colonização e na sua relação com a Notre Dame. Talvez, iniciar por apresentar algumas características do Clube de Mães, sendo ela uma associação escolar nesse contexto, pois sua relação era direta com as famílias dos alunos do Grupo Escolar Nossa Senhora da Salete de Maravilha/SC. Além disso, no próprio documento pesquisado de
1959 é utilizado o termo associação, para se referir ao Clube de Mães.

\section{Clube de Mães}

As reuniões dessa associação escolar se transformavam em um espaço de construção da representação da família para aquele momento. No dia 23 de agosto de 1959, aconteceu a segunda reunião do Clube de Mães. Não foi encontrada até o momento a data da criação do clube com a primeira reunião. A citação a seguir evidencia que a associação foi criada neste mesmo mês, ou seja, em agosto de 1959: "Devido à doença da irmã ficou um pouco parada esta associação, mas logo no primeiro mês de atividade foi reorganizado" (ANAIS CASA N. S. DA SALETE, 1959, p. 27).

A associação escolar possuía 97 sócias. Tendo como orientadora a irmã Maria Ancila, as reuniões versavam, sobretudo com relação à educação dos filhos, mas principalmente das filhas e de modo geral, sobre a família. Dessa forma, era abordado o assunto sobre o papel da mulher no lar e na sociedade, principalmente o de mãe, ou seja, sobre a família era enaltecida a: "[...] importância da mãe para a felicidade do lar, necessidade de colaboração entre a família e a escola, como satisfazer o marido para que haja paz na família etc. [...]" (ANAIS CASA N. S. DA SALETE, 1959, p. 27). Nessa mesma linha de temas abordados, estava a preparação das moças para o casamento. Esses encontros ocorriam a cada dois meses. Havia uma biblioteca com livros, especialmente para as moças que aspiravam ao matrimônio. As conversas eram permeadas por conselhos que eram dados para que as filhas fossem preparadas para o matrimônio, de forma primordial.

Uma mãe inteligente saberá fazer de sua família uma pequena e agradável sociedade, fazer tanto como seus filhos e esposo se sinta bem no lar. Não basta proibir aos filhos, você não vá lá, em tal sociedade, ou não leia esta revista ou livro mau, é preciso já, antes de tal cousa tirar-lhe [...] Como por exemplo ter um rádio em casa, não sai tão caro e é útil e instrutivo. Não recalcar ou 
inibir o espírito de curiosidade sexual mas em tempo oportuno quando o filho perguntar devemos orientá-lo. Conduzi-lo para seu pleno e sadio desabrochamento dentro de uma esfera moral e religiosa, principalmente as mães preparem as filhas antes do casamento. Não ter vergonha de falar, pois por esse falso pudor talvez quantas lágrimas terá de verter sua filha (LIVRO DE ATAS do Clube de Mães , nº 1, 28 de maio de 1961).

A centralidade do homem como chefe da família era legitimado nos discursos e nos conselhos dados nas reuniões. Era um poder, com seu discurso legitimado para esse momento. Esse discurso emanava das reuniões, saía de dentro dos muros da escola para chegar até os lares das famílias, pelo menos as que tinham seus filhos na escola. Pode-se afirmar, talvez, que ocorria uma relação de poder, a qual constituía o corpo social a partir do funcionamento do discurso. Um discurso que apresentava o papel do homem como chefe da família, pois:

A seguir acrescentou ainda a Revda. Irmã Orientadora, as mulheres sejam submissas, a seus maridos como ao Senhor, pois o marido é o chefe da mulher, como Cristo é o chefe da Igreja, [...]. Nós como religiosas mesmo dum certo modo também dependemos do homem. (ATA CLUBE DE MÃES n ${ }^{\circ} 02$, 1961, p. 2).

Com relação ao funcionamento do discurso, Foucault (2005, p. 179) afirma que:

Em qualquer sociedade, existem relações de poder múltiplas que atravessam, caracterizam e constituem o corpo social e que estas relações de poder não podem se dissociar, se estabelecer nem funcionar sem uma produção, uma acumulação, uma circulação e um funcionamento do discurso.

O Clube de Mães formava um braço da Congregação de Notre Dame. Nos Anais da Casa Nossa Senhora da Salete do dia 23 de agosto de 1959, constam a seguinte definição: "Uma das instituições mais bem organizadas que temos em nossa Escola [...] é a parte feminina da Associação de Pais e Mestres também em pleno funcionamento em nossa escola”. Diferentemente, da Associação dos Pais, que tratava de diversos assuntos de administração e organização, o Clube de Mães, tratava das coisas pertinentes ao trabalho da mulher e esposa no lar, no controle e vigilância da moral das famílias do povoado.

O papel desempenhado por esses atores dentro dessas associações é aquele que deveria ser desempenhado no lar, ou seja, a mulher mãe cuidando da moral da família, dos filhos e o pai cuidando da administração. Os temas principais que eram abordados nas reuniões do Clube de Mães se referiam à supremacia do homem sobre a mulher. Como tratar com gestos delicados o marido, para que este não ficasse zangado. Se tornar uma "rainha do lar". Era o esperado do papel desempenhado pelas mães que participavam das reuniões e também:

A educação das crianças, importância da
Mãe para a felicidade do lar, necessidade
de colaboração entre a família e a escola,
como satisfazer o marido para que haja
paz na família etc. [...]. As mães ficam
sempre muito contentes. Dizem que
poderiam ficar o dia todo escutando
a irmã falar. Grandes tem sido os
frutos destas reuniões. São realizadas
geralmente de dois em dois meses.
Tem a diretoria bem constituídas a
secretaria lavra fielmente as atas. Temos
uma biblioteca mais ou menos bem
organizada, só para as mães e moças
que espiram ao matrimonio. Pagam
Cr\$ 40,00 anuais para retirar uma vêz
por semana um livro. (ANAIS CASA
NOSSA SENHORA DA SALETE, 23 de
agosto de 1959, p. 27).

As conversas nas reuniões se davam no sentido de preparar as filhas, menos para os estudos do que para o casamento. No dia 28 de maio de 1961, em uma reunião do Clube de Mães, presentes 43 sócias e irmã Maria Ancila que apresentava, por uma vez mais, os elementos que legitimavam a ação do clube, ou seja:

Unir a família a bôa escola para a defesa dos direitos sagrados da família, 
principalmente contra as forças externas que procuram fazer vacilar as bases da família. Uma mãe inteligente saberá fazer de sua família uma pequena e agradável sociedade, fazer tanto como seus filhos e esposo se sintam bem no lar. (ATA CLUBE DE MÃES nº 1, 1961, p. 1).

O objetivo era o de delegar à mulher o papel de zelar pela moral e bons costumes da família, ou seja, desempenhar o papel de "rainha do lar". Das reuniões, para o povoado, os ensinamentos eram difundidos, para que:

Procurassem tudo fazer para serem mesmo o sol do lar. Dentro sim de suas possibilidades cuidar muito da aparência pessoal para agradar o esposo. Muitas relacham em aparecer bonitas e pensam "ha eu tenho o meu" sim acrescentou tu tens o teu então segura-o faça com que o se sinta atraído ao lar é teu dever também. Finalizou explicando "ha economias que custam caro”. (ATA CLUBE DE MÃES n ${ }^{\circ} 1$, 1961, p. 1).

No povoado, funcionando como auxiliares, as associações escolares, principalmente o Clube de Mães, atravessavam os muros da escola, indo ao encontro dos lares das famílias. Para os lares, o direcionamento era que: "[...] cada família deveria ter uma bíblia em casa e na hora das refeições fosse lido um trechinho para assim difundir melhor o cristianismo em nossas famílias" (ATA CLUBE DE MÃES no 10, 1966, p. 7).

Nas reuniões do Clube de Mães, além de se abordar a questão moral da família, as participantes costuravam uniformes para os alunos pobres. Não obstante havia as:

Representantes Sociais que: encarregadas da criança pobre andaram de casa em casa oferecendo assim oportunidade de frequentar as aulas a diversas crianças pobres que não frequentavam. [...] não deixaram de cumprir a missão de que foram encarregadas, em vigiar o comportamento dos colegiais na sociedade (RELATÓRIO CLUBE DE MÃES, 1966, p. 9).
A vigilância ocorria dentro e fora dos muros da escola, moldando o comportamento do aluno na sociedade. Como se percebe na passagem anterior, muitas crianças que eram de famílias pobres não frequentavam a escola. Ou seja, temos aí uma evidência de que era considerável o número de crianças pobres que não frequentavam as aulas nesse momento. A vigilância dos lares se dava pelos ensinamentos que a ordem religiosa prescrevia às mães.

As reuniões conduzidas pela irmã Maria Ancila, diretora do Grupo Escolar, voltavam-se para a maneira de educar os filhos. A religiosa explicava que a mãe tem o dever de castigar seus filhos quando eles merecerem; afinal:

Nesta altura a D.D. Orientadora leu-nos uns trechos da Bíblia sobre "Autoridade do homem no lar" e Poema alfabético sobre a mulher virtuosa. Cujos trechos tanto agradou as ouvintes que umas já prometeram comprar a Bíblia e outras as que tem de estudá-la mais.[...] as mulheres sejam submissas, a seus maridos como ao Senhor, pois o marido é o chefe da mulher, como Cristo é o chefe da Igreja, seu corpo, da qual êle é o Salvador. Nós como religiosas mesmo dum certo modo também dependemos do homem. [...] que a esposa e mãe mantenha-se sempre calma e aja com maneiras delicadas. Desta maneira conseguirá tudo de seu esposo, bem como de seus filhos. [...] a mãe tem o dever de castigar seus filhos quando estes merecerem. Acrescentou que: quem mais executa seus filhos, mais gosta deles. Os pais não devem fazer a vontade do filho, não expor-se a muitas brincadeiras com ele e nem rir quando este pratica uma má ação (ATAS DO CLUBE DE MÃES, 5 DE MAIO DE 1962, p.4).

A moral cristã, além de presente no espaço escolar, era difundida além dos muros da escola, uma vez que regia a vida social e os costumes familiares no povoado. Um exemplo disso é que, no dia 11 de maio de 1965, a irmã Ancila conclamou as mães a se unirem contra a abertura de uma "casa de corrupção" que estava prestes a abrir na cidade, considerando tal fato como sendo "perigoso" (ATA CLUBE DE MÃES nº 09, 1965, p. 7). 


\section{Bandeira da Cruzada Eucarística}

No dia 31 de maio de 1962, houve o ingresso de crianças nessa cruzada:

Já há vários meses que os nossos pequenos estão se preparando a fim de ingressarem no número dos soldados de Cristo sob a "Bandeira da Cruzada Eucarística”. Neste dia tão festivo para êle se reuniram no pátio da escola, onde sob a direção da irmã Maria Ancila e dos apóstolos da Cruzada, foram conduzidos em procissão até a igreja, onde após um lindo sermão receberam a insígnia de "Cruzados" ou aspirantes da Cruzada. E a seguir houve Santa Missa (ANAIS CASA NOSSA SENHORA DA SALETE, 1962, p. 50).

No ano de 1961, no dia 21 de abril, novos membros ingressaram na Cruzada Eucarística, passando a contar nessa data com 83 cruzadinhos, como eram chamados os integrantes dessa associação escolar. Outra atividade que era levada a cabo por essa cruzada, no auxílio à Notre Dame, era o batismo de famílias convertidas, como ilustra o exemplo apresentado a seguir:

O senhor Egom Dispsel, era protestante, mas sua esposa é católica, e ele não se sentiu feliz ao ver que as crianças rezavam e a mãe as ensinava e êle não podia ensinar-lhe nada pois nada sabia da nossa religião para poder ensinar os pequenos. Por isso se tornou católico; mas a mais feliz foi a sua esposa que agora poderia novamente receber os sacramentos, que desde o dia do casamento não mais os recebeu em vista que ficou excomungada por ter se casado em uma outra religião. Foi batizado o pai e os três filhos o pai fez neste mesmo dia a $1^{\text {a }}$ Comunhão. (ANAIS CASA NOSSA SENHORA DA SALETE, 1961, p. 44).

Os Cruzadinhos atuavam junto às crianças e adultos. Os batismos, muitas vezes, serviam para a conversão com o objetivo de casar ou de manter o casamento. No dia 3 de fevereiro de 1959, houve o batismo de duas moças que pertenciam à:
[...] Igreja Missurri e querendo casarse com rapazes católicos [...] depois de terem recebido durante um mês instrução católica em nossa casa foram batizadas e fizeram a $1^{\text {a }}$ Comunhão. Infelizmente uma delas não ficou católica fervorosa como devia ser. (ANAIS CASA NOSSA SENHORA DA SALETE, 3 fev. 1959).

Em dezembro de 1960, foi realizada mais uma cerimônia de batismo, quando:

Hoje foi batizada toda a família do Sr. Arlindo Anel. Já há muito tempo que a sua espôsa estava sempre em dúvidas, ela via que estavam no caminho errado e queriam entrar no caminho que conduz verdadeiramente ao céu. Por isso começou-se o trabalho da catequese, e no dia 7 de dezembro foram batizados todos em nossa capela. Em primeiro lugar o pai e a mãe deviam abjurar ao protestantismo, isto as crianças não precisaram porque ainda não eram confirmadas na igreja protestante, seguiu o batismo de todos, eles mesmo respondiam as perguntas do padre com exceção da mais pequena que tem só seis meses, foram sete batismo de uma vez só o pai Arlindo a mãe Erna e as quatro filhas Sonélia, Erecilda, Neusa e Elaci e o filho Irineu, no dia seguinte o pai e a mãe e as duas filhas mais velhas fizeram a primeira Comunhão em uma missa solene em nossa capela. (ANAIS CASA NOSSA SENHORA DA SALETE, 8 dez. 1960).

A família que não era batizada na Igreja Católica era vista como uma família que estaria no caminho errado, pois, se permanecesse no protestantismo, não andaria no caminho que conduz "verdadeiramente ao céu". O trabalho da catequese se tornava a ação por meio da qual a família seria moldada dentro dos preceitos cristãos e encontraria a salvação.

Depois da missa, naquele dia 3 de fevereiro de 1959, todos regozijaram com um café na casa Nossa Senhora da Salete das irmãs, pois: "Num aprisco cabem muitas ovelhas mansas' isto é mesmo verdade, pois numa sala que durante o ano só cabiam 20 pessoas agora tinha 50 e todos tinham 
o seu lugar para sentar" (ANAIS CASA NOSSA SENHORA DA SALETE, 8 dez. 1960).

Com relação às associações tematizadas nesse texto, é mister e oportuno tomar emprestado a afirmação de Rioux (2003, p. 10), que afirma:

A reunião de pessoas é primordial, porque esses voluntários são impelidos pela "necessidade de estabelecer um novo tipo de controle social que determine seu lugar na sociedade", tanto quanto pela promoção da ideia geradora ou pelo respeito ao fundador de seu agrupamento.

Rioux (2003) afirma que se a associação tem várias tarefas na sociedade, atendendo emergências e estancando sangramentos no corpo social, já que a administração do Estado ao se voltar para suas próprias regras e leis, entrega essas tarefas à ela, então "[...] entendese que é preciso fazer a história dessa conquista da sociedade pela associação que caracteriza o século XX" (RIOUX, 2003, p. 119). Para apresentar aqui apenas uma definição de associação, talvez possa ser a questão seguinte:

E o que é ela então? Uma estrutura cômoda para a emergência de novas elites? Um corpo intermediário indispensável entre o cidadão e os poderes, dentro do qual a democracia voltaria a beber em suas fontes ou se preservaria das tentações do estatismo ou mesmo do totalitarismo, essas doenças do século? (RIOUX, 2003, p. 119).

Seriam as nossas associações, no caso específico desse texto, uma bolha para formação de elites? Ou uma forma de tornar os corpos dóceis e disciplinados para o trabalho? Enquanto isso, os eventos, como festejos religiosos, se entrelaçavam com o período letivo no Grupo Escolar, pois:

Sessenta crianças foram preparadas durante o ano letivo para a Primeira Eucaristia. A criança fazia parte de um grupo reduzido que era preparado por uma irmã ou professôra leiga. A ir. Ma. Orielde orientava tudo. Ela tinha feito um cursinho para tal finalidade em
Chapecó. Foi muito bonito. No final da Santa Missa cada criança era chamada e os pais vinham recebê-la no altar e a conduziam para fora. (ANAIS CASA NOSSA SENHORA DA SALETE, 1970, p. 100).

A formação religiosa estava em consonância com a formação escolar. A associação escolar, Bandeira da Cruzada Eucarística, como se percebe a partir da investigação dos documentos, realizava uma frente que atuava junto aos moradores da comunidade. Uma família inteira poderia ser batizada e convertida para a Igreja Católica. Os soldados de cristo, que eram os alunos do Grupo Escolar, também conhecidos como cruzadinhos, funcionavam como se fossem sensores de Notre Dame. Acontecia um cerimonial junto à família para desligá-la do protestantismo. Antes de qualquer coisa, os pais precisavam abjurar ao protestantismo. As crianças não o precisavam fazer, pois ainda não tinham sido confirmadas no protestantismo. No dia seguinte desse desligamento do protestantismo, essas pessoas adultas já faziam a primeira comunhão.

\section{Pelotão da Saúde}

Os historiadores estariam incorrendo em sério erro se buscassem em suas investigações, modelar-se pela cronologia dos acontecimentos, simplesmente. Aliás, ao invés de primar pelo tempo rápido dos eventos, o historiador deve considerar a importância de se aprofundar nas realidades que mudam lentamente, as estruturas como a geografia, a cultura material e as mentalidades, ou seja, o tempo da longa duração, uma história quase imóvel (LE GOFF, 1990). Torna-se possível, assim, construir uma concepção de que a educação dessa segunda metade do século XX não é a mesma do século XIX; porém, tendo em mente que na história há rupturas e descontinuidades, existe também realocação de problemas.

Dessa maneira, a ação da associação escolar, em análise aqui, foi permeada por mecanismos de controle, que são verificados ainda na Primeira República (1889-1930) e fizeram eco na segunda metade do século XX. É perceptível, quando se 
analisa a presença institucional da Igreja Católica nas ações educacionais no início da Primeira República, pois Sousa (2003, p. 161), afirma que: "[...] a disciplina, o controle e a repressão no meio escolar deveriam assegurar a formação de uma infância identificada com o paradigma do bom CIDADÃO, do bom REPUBLICANO e do bom CRISTÃO”.

A ação do Pelotão da Saúde, como associação, no Grupo Escolar Nossa Senhora da Salete, se aproximava de um discurso médico. É possível afirmar isso, a partir da ideia de que, sendo o espaço escolar um local de aplicação de tecnologias governamentais, o sistema educacional é chamado a intervir na realidade e no comportamento moral e sexual das crianças. Historicamente a medicina priorizou um saber/poder também no espaço escolar. Não obstante, o corpo da criança era alvo desse saber/poder (ALTMANN, 2009).

A ata número 1, do dia 9 de março de 1968, escrita pela secretária Rosani Bernardi, revela que, às 3 horas da tarde desse dia, tendo por local o galpão da querência, na sala do $4^{\circ}$ ano, realizou-se a primeira reunião do Pelotão da Saúde, cuja orientadora foi irmã Helmine, que orientava também as demais associações. Composto por uma diretoria, o evento tinha em cada classe dois monitores, que faziam uma revista higiênica. Essas inspeções aconteciam todas as sextas-feiras. Os integrantes usavam avental e capacete brancos. A classe vencedora, após terem sido feitos os trabalhos de revista, recebia uma bandeira branca que permanecia na sala até a próxima visita, pois:

Assim sempre todos queriam ganhar a Bandeirinha e vinham limpos para a escola. [...] As reuniões foram feitas em junho e marco e agora no fim do ano. Em todas elas, foi sempre falado sobre a limpeza, ordem e asseio que devem haver entre os alunos. Por isso fizemos todas as semanas a revista. Alguns monitores se distinguiram pelo interesse que mostraram em conservar sempre o pátio limpo e também as privadas, quase todos os dias as lavamos, e ensinamos aos pequenos como comportar-se neste lugar. Temos duas bandeiras novas, uma para o turno matutino e a outra para o vespertino. (RELATÓRIO FINAL PELOTÃO DE SAÚDE, 1959, p. 23).

A partir da passagem citada, é possível perceber que o Pelotão da Saúde já existia antes, ou seja, tratava-se de uma associação auxiliar que já atuava nos primeiros momentos da presença de Notre Dame no povoado. A direção que tomava essa associação era no sentido de se aproximar com seus ensinamentos junto aos alunos do grupo escolar.

Tinha reunião em março e agôsto e no fim do ano. Nestas reuniões a orientadora sempre insistiu na ordem, asseio e higiene. Os monitores se esforçaram para conservar a ordem e o asseio nas patentes e também no pátio e nunca zombaram de um aluno que não estava limpo. (RELATÓRIO ANUAL GRUPO ESCOLAR N. S. DA SALETE, 1957, p. 57).

O Pelotão da Saúde possuía em 1969 um pequeno pronto-socorro com medicamentos para atender alunos que se machucassem. Além disso, cuidava da limpeza e da ordem do pátio da escola, ensinava como manter a higiene do corpo e outras ações que realizava desde sua criação. A metodologia consistia em os fiscais andarem pelo pátio e pelas sanitárias durante o recreio, a fim de observar o comportamento higiênico e a ordem dos alunos. Como neste ano de 1969 a escola estava sem serventes, o Pelotão ficou responsável por passar em todas as salas ao final das aulas. As turmas que deixavam a sala mais limpa eram premiadas com algum atrativo como um filme de slides, por exemplo (RELATÓRIO GERAL GRUPO ESCOLAR N. S. DA SALETE, 1969, p. 39).

Foucault (2005) afirma que no século XVIII a saúde e o bem-estar físico se tornam um objetivo político que a "polícia" do corpo social deve regular ao lado das questões econômicas e da ordem. Esta ordem higiênica era disseminada também pelas instituições de caridade e religiosas. Estas atribuições higiênicas vinham acompanhadas de atividades de distribuição de vestuário, amparo a crianças pobres abandonadas, educação moral e vigilância sobre mendigos e indigentes. Com a atuação dessas 
associações auxiliares de Notre Dame, o discurso normalizador de higiene, ordem e disciplina eram difundidos com o objetivo de adestrar os corpos, para torná-los limpos, disciplinados e patrióticos.

$\mathrm{Na}$ reunião do dia 3 de maio de 1968, o assunto abordado foi sobre o uso do lenço. Parece que, pelo menos, uma considerável parcela de alunos do Grupo Escolar utilizava-se de lenço de pano para fins de higiene. A fiscalização era rigorosa. Na reunião, ficou certo que: "Na próxima semana os encarregados farão revista do lenço; a meio da semana se fará uma revista geral em todas as classes; e falou-se, ainda, da maneira de usar o lenço corretamente" (ATA PELOTÃO DA SAÚDE, 3 de maio de 1968, p. 2).

No ano de 1965, a festa de encerramento das atividades, ocorrida no dia 13 de dezembro, evidencia toda uma atmosfera religiosa com sua disciplina e vigilância. Houve o encerramento das atividades com as crianças do jardim de infância, com uma festinha embaixo de um pessegueiro com bandeirinhas e um presépio com a presença das mães, entoando "poesias para o Menino Jesus". Também houve o encerramento para:

Aqueles professôres que tinham a responsabilidade de alguma atividade extra como Clube Agrícola, Pelotão da Saúde, Liga da Bondade, Biblioteca, etc., começaram a movimentar-se para apresentar o Relatório dos trabalhos durante o ano. Não se tinha tempo para perder. (ANAIS CASA NOSSA SENHORA DA SALETE, 1964, p. 65).

Assim, fechava-se a cortina de mais um ano, com os professores finalizando os trabalhos junto às associações escolares de Notre Dame. Destaca-se o cuidado que se dava para a atuação dessas associações, consideradas vetores de valores e condutas que eram difundidos dentro e fora dos muros do Grupo Escolar.

\section{Considerações finais}

A escolha pelo tema deste artigo se deu no sentido de considerar que o que foi apresentado, suscita discussões e curiosidade de um momento singular, composto por uma atmosfera cujas relações eram permeadas por dispositivos de controle e disciplina e por um poder que circulava, visto que as associações escolares tinham papel preponderante no auxílio às atividades da Congregação de Notre Dame.

Sobretudo no meio acadêmico, essa pesquisa não deixa de ter a pretensão de contribuir para a historiografia da colonização e da ocupação do espaço do Oeste Catarinense, pelos migrantes que vieram do Rio Grande do Sul e aportaram nessas inóspitas paragens. Principalmente no que se refere à análise das relações de como a escola afetou a comunidade como um todo, com o auxílio das associações escolares. Não há muitas dúvidas, de que estudar essas associações possa contribuir para contar a história da colonização.

Não menos importante é o fato de que, ao estudar essas associações, revelam-se várias ações que as transformaram em um braço da ordem religiosa presente no espaço da colonização: Notre Dame. O resultado da análise dos documentos aponta no sentido de que a existência do Clube de Mães, por exemplo, visava a estabelecer padrões de conduta moral nas famílias. Dessa forma, as associações escolares ligadas ao Grupo Escolar Nossa Senhora da Salete: o Clube de Mães, a Escola de Pais e Mestres, Os Cruzadinhos, o Pelotão da Saúde, a Liga da Bondade, a Liga Pró-Língua Nacional e o Clube Agrícola - algumas delas, não abordadas nesse texto - tornaram-se mecanismos de controle e disciplina, por difundirem valores para a construção de um espaço ordeiro e de progresso.

\section{Notas}

1 Conforme Farge (2009, p. 15).

2 Aqui tomo emprestada a definição de Arlene Renk (2006, p. 9): "Por oeste catarinense, tomo aqui a área compreendida nos limites fixados em 1917 aos municípios de Cruzeiro (atual Joaçaba) e Chapecó, que corresponderia atualmente às regiões coloniais do oeste $\mathrm{e}$ do Rio do Peixe, na divisa utilizada pelo IBGE".

3 Frequentemente o termo "vila", às vezes "povoado", aparece nos documentos, para se referir ao local, antes da emancipação em 1958. Porém, não significa que não tenha sido usado também após a emancipação.

4 Em relação ao Seminário Nossa Senhora de Fátima, a Cia. Sul Brasil doou o terreno para a sua construção. 
A Colonizadora sabia da necessidade de os colonos praticarem sua religiosidade e de seus filhos terem acesso à educação, pois isso era um fator determinante para a expansão da colonização. A história do Seminário em Maravilha está intimamente ligada aos padres Missionários da Sagrada Família e sua atuação se delimitaram a área localizada entre os rios Uruguai, Antas e o Chapecó, região colonizada pela Cia. Sul Brasil.

5 Conforme Arlene Renk (2006, p. 9): “Colono é a designação atribuída à população rural. O qualitativo de origem é a forma como são identificados os descendentes de europeus, aqui tomados genericamente".

6 Com o objetivo de considerar a construção da documentação, se transformando assim, num elemento a mais para se compreender as relações do período pesquisado, optou-se por não atualizar a grafia dos documentos, não seguindo as atuais normas ortográficas da língua portuguesa.

\section{Referências}

ALTMANN, Helena. Corpo e gênero na educação sexual: análise de uma escola carioca. In: HEILBORN, Maria Luiza (Org.). Sexualidade, Reprodução e Saúde. Rio de Janeiro: FGV, 2009. p. 342-360.

ANAIS DA CASA NOSSA SENHORA DA SALETE. Arquivo Passivo Casa Provincial de Notre Dame, Passo Fundo - RS, 1958 - 1959 - 1960 1961 - 1962 - $1964-1970$.

ATA CLUBE DE MÃES. Arquivo Passivo EEB. Nossa Senhora da Salete, 1961- 1962 - 1965 - 1966.

ATA DO PELOTÃo DA SAÚDE. Arquivo Passivo EEB. Nossa Senhora da Salete, 1968.

CARTA À CIA. SUL BRASIL. Arquivo Museu Municipal Padre Fernando Nagel, Maravilha/SC, 26 maio 1952.
FARGE, Arlette. O sabor do arquivo. São Paulo: Editora da Universidade de São Paulo, 2009.

FOUCAULT, Michel. Microfísica do Poder. Rio de Janeiro: Graal, 2005.

LE GOFF, Jacques. História e memória. Campinas: Editora da UNICAMP, 1990.

RELATÓRIO FINAL PELOTÃO DE SAÚdE. Arquivo Passivo EEB. Nossa Senhora da Salete, 1959.

RÉMOND, René. Por uma história política. Rio de Janeiro: FGV, 2003.

RENK, Arlene. A luta da erva: um ofício étnico da nação brasileira no oeste catarinense. 2. ed. rev. e atualiz. Chapecó: Argos, 2006.

RIOUX, Jean Pierre. A associação em política. In: RÉMOND, René. (Org.) Por uma história política. Rio de Janeiro: Editora FGV, 2003. p. 99-139.

ROUSSO, Henry. A última catástrofe: a história, o presente, o contemporâneo. Rio de Janeiro: FGV Editora, 2016.

SOUSA, Rogério L. de. As escolas Paroquiais. IN: DALLABRIDA, Norberto (Org.). Mosaico de Escolas: modos de educação em Santa Catarina na primeira República. Florianópolis: Cidade Futura, 2003. p. 155-173.

WERLANG, Alceu Antônio. Disputas e ocupação do espaço no oeste catarinense: a atuação da Companhia Territorial Sul Brasil. Chapecó: Argos, 2006. 